\title{
Features of Aboveground Pipeline Compensation Part Stress-Deformed Study at Permafrost
}

\author{
Dinar Flerovich Bikmukhametov ${ }^{1}$, Gennady Evgenyevich Korobkov ${ }^{1} \&$ Anna Pavlovna Yanchushka $^{1}$ \\ ${ }^{1}$ Ufa State Petroleum Technological University, Russian Federation \\ Correspondence: Dinar Flerovich Bikmukhametov, Ufa State Petroleum Technological University, Russian \\ Federation.
}

Received: January 15, 2015

Accepted: February 3, $2015 \quad$ Online Published: July 30, 2015

doi:10.5539/mas.v9n8p204

URL: http://dx.doi.org/10.5539/mas.v9n8p204

\begin{abstract}
The gradual shift of the Russian Federation oil production center to the areas with difficult climatic conditions, states additional challenges to the Oil production companies during development of these regions. Impossibility of underground design of oil pipelines in waterlogged areas, areas with subsurface voids unstable of different origin, permafrost zones, landslide zone forces companies to focus laying pipelines by above ground manner. The purpose of this article is to present a review of the stress-deformed state of the aboveground pipeline, its behavior during operation and pressure test stage, the forces acting on the pipeline. The study allows us to understand the state of the pipeline, to assess its stability and reliability. Analyzing the research results, it must be concluded that the decision of choice the above ground pipeline design (route geometric parameters), should be performed, guided not only meet the conditions of strength, as well as other reasonable important factors: the values of the forces acting on the fixed supports, three-dimensional position of the pipeline during hydraulic testing and operation, vibration in the pipeline, the impact of ambient temperature, wind resistance aboveground pipeline, further arising forces affecting piping supports, due to thawing of ground and soil bulging, etc.
\end{abstract}

Keywords: stress-deformed state of the pipeline, above ground pipeline, pipeline at difficult geotechnical conditions

\section{Introduction}

Today, Western Siberia is the leading oil-producing region of the Russian Federation. However, according to predictive estimates, about $60 \%$ of the deposits of Western Siberia are in the stage of production decline. The reasons for this are several: the physical resources exhaustion, lack of investment in geologic exploration and ineffective production methods. At these conjunctures, today analysts predict a gradual shift the center of oil production from Western Siberia to the Eastern Siberia. Hydrocarbon fields depletion in developed areas, technical and economic constraints associated with the heavy oil extraction, bituminous sands development - all these circumstances objectively determine displacement of oil and gas development center into the new regions: the Yamal Peninsula, Eastern Siberia, Far East and shelf of Russian Federation (Abovskiy, 2005).

These regions are characterized by extremely difficult geotechnical conditions (Borodavkin et al., 1974), such as wetlands and waterlogged areas, areas with subsurface voids of different origin (area with cave formations, undermined territories in the areas of mine construction, etc.), permafrost zones, landslide zones, earthquake endangered zones, rugged terrain (Shammazov et al., 2005).

Due to the gradual shift the center of oil and gas production in these areas attention to the pipeline laying increases. Field development in such areas requires a huge amount of investments, main part of which shall be intended to implementation of technologically and structurally safe pipeline systems. Under these circumstances, evaluation of the stressed-deformed state of such pipelines is becomes extremely valuable (Vitchenko, 2008.).

During the construction and operation of oil and gas transportation pipeline systems occurs introduction their technological elements in the natural environment (Petrov and Spiridonov, 1973). This is often done in violation of the dynamic equilibrium, accompanied by activation of natural hazardous processes that have a significant negative impact on the technical condition of the pipelines often lead to the accident. Among such "rejection reactions" of natural environment include Structure subsidence or bulging, activation of permafrost, erosion, landslides and flooding on the pipeline routes all these processes belong to such "rejection reactions" of natural environment 
(Borodavkin and Berezin, 1974).

Above Ground pipelines in many cases, the most economically viable and feasible from the design, technological, construction and operation of the pipeline point of view. Above Ground laying of pipelines is usually applied in complex geological and hydrogeological conditions, such as marshy and flooded areas, in areas with frequent ravines, streams and other obstacles, on the rocky soil and in permafrost conditions (Khrenov, 2005).

\section{Method}

This research was base on the study of stressed-deformed state of aboveground oil pipeline considering of the really existing aboveground pipeline part in the Komi Republic. The pipeline is laying in the permafrost zone, at very low temperatures and complex natural and geological conditions. The route of the pipeline passes trough the multi-year frozen soil with a temperatures $-6-7^{\circ} \mathrm{C}$. The water saturation of the ground reaches $70 \%$. Ice content is $10-20 \%$, and the ice flat sheet deposits reach several tens of meters thickness, at some places they are cryopegs. The pipeline route crosses a large number of rivers and streams. The intensively occur frost heaving cause major deformation of the supporting part of the pipeline. Currently, the land pipeline construction in such circumstances is almost have not reliable engineering solutions to ensure provision of general and longitudinal stability of the pipeline, and therefore, there is no guarantee to ensure their reliable operation. The route passes in difficult engineering-geological, climatic and environmental conditions, in many places in marshland, in the permafrost. The combination of these conditions determines the complexity of the construction and operation of the pipeline.

There are oil, gas and water pipelines laying in one right-of-way, but for the stressed-deformed state consideration it was taken the part of the aboveground oil pipeline shown on the picture, lbetween 2 fixed supports near Block Valve Station (BVS) \#2.

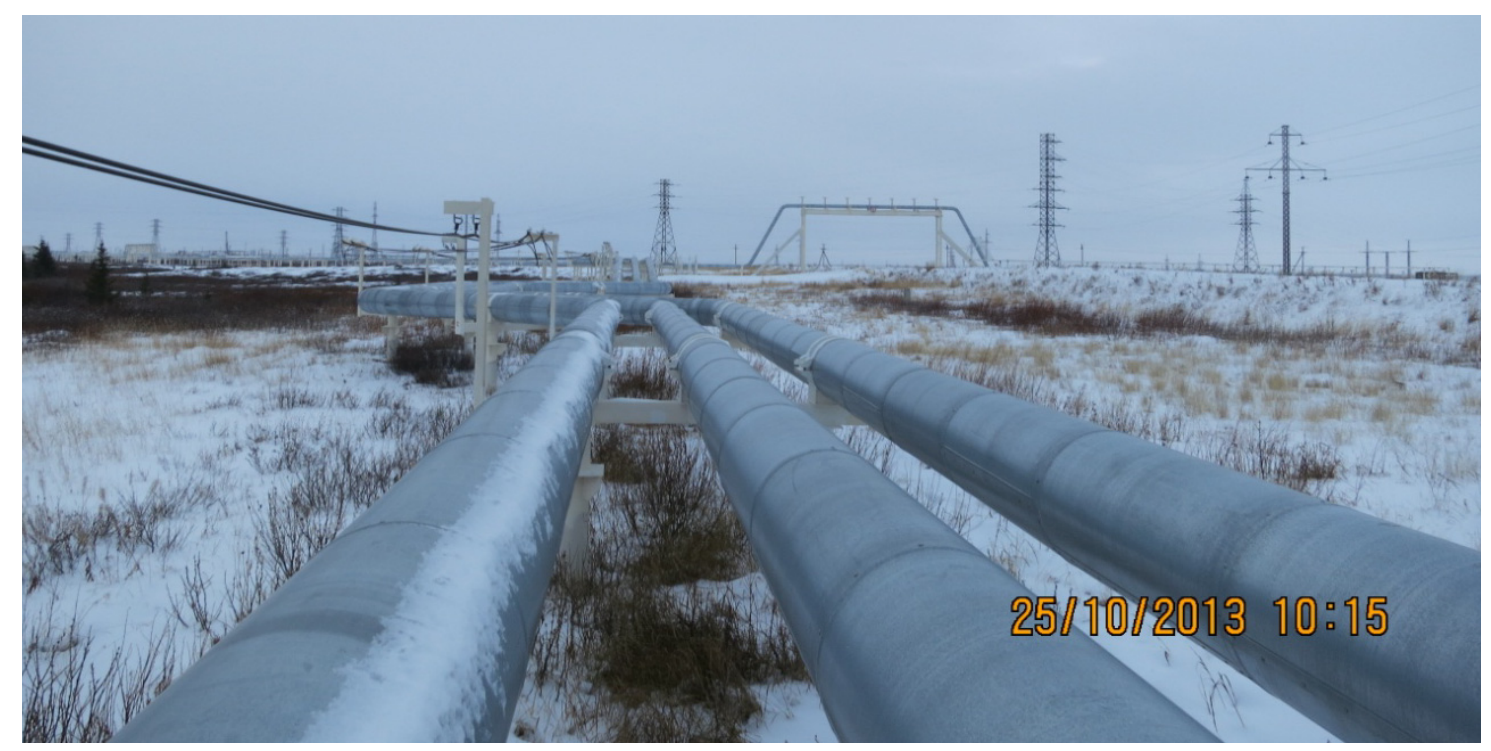

Figure 1. Part of the aboveground pipeline with a diameter of $220 \mathrm{~mm}$

To study the stressed-deformed state of the aboveground oil pipeline part, as well to analyze of the pipeline displacement study part of the pipeline has been modeled in accordance with the design and technical documentation in software "Start", represented on the Figure 2. The modeled part of the aboveground pipeline contains of: 2 fixed supports at the ends \#400, \#411; 6 different angle elbows \#500 - 505; 10 sliding supports \#401-410; 1 Emergency Shut Down Valve (ESDV) - \#600. 


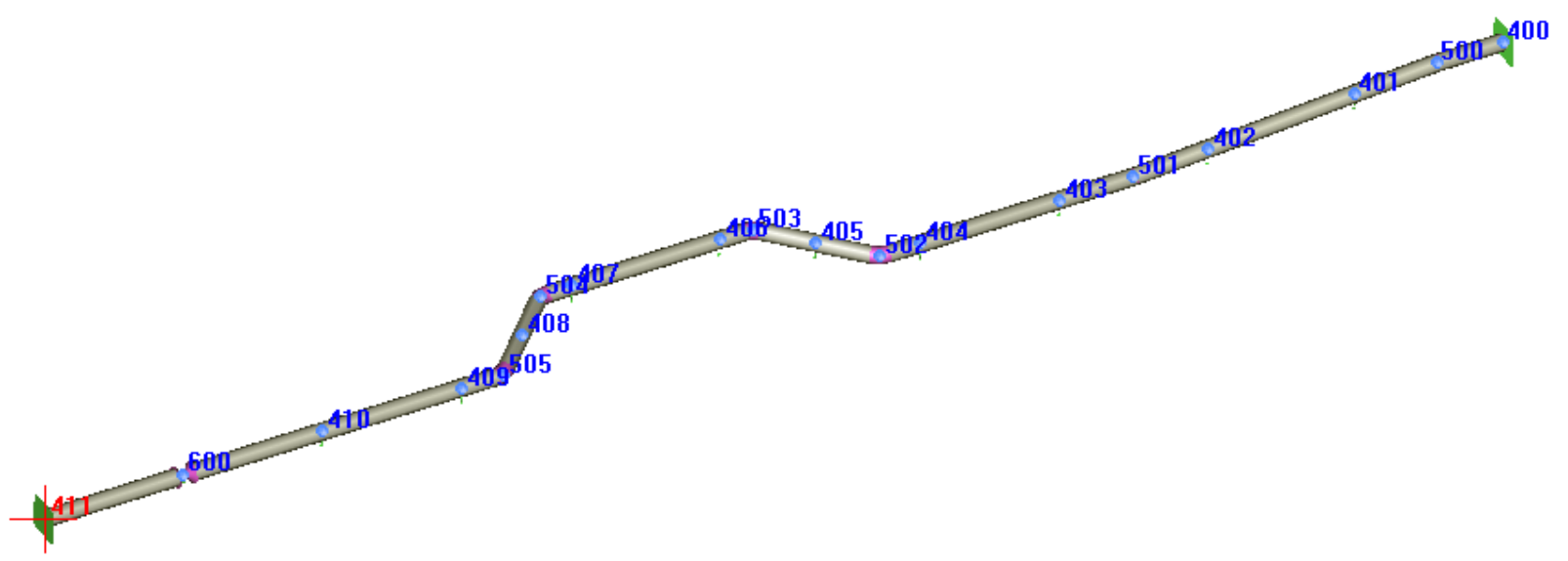

Figure 2. Modeled part of the above ground oil pipeline in «Start» software

Input data for calculation:

Installation temperature $-(-30)^{\circ} \mathrm{C}$;

The test liquid - water;

Test temperature $-(10)^{\circ} \mathrm{C}$;

External pipe diameter $-219,1 \mathrm{~mm}$;

Nominal wall thickness of $14,3 \mathrm{~mm}$;

Pipe material - 10G2FBYU;

Operating Pressure $-13,9 \mathrm{MPa}$;

Design temperature $-(42,5)^{\circ} \mathrm{C}$;

Test pressure - $20.85 \mathrm{MPa}$.

Based on the data and operating conditions "START" software varied out the strength calculations of the pipeline. The software product is capable to simulate the behavior of the pipeline, as well as to determine the three-dimensional position of the pipeline sections during the operation and hydraulic tests stages.

The program calculates the circular, longitudinal and equivalent stress. According to the method of limiting conditions on Construction norms and rules (SNIP) 2.05.06-85 (SNiP 2.05.06-85, 1985) program calculates ultimate strength designed resistance R1 and the calculated yield strength designed resistance of R2 (Ainbinder and Kamerstein, 1982). Also, the software calculates the total forces acting on the pipeline and determines the values of pipeline displacement during operation and hydraulic tests. For this pipeline R1 $=2322,58$ (kgf $/ \mathrm{sq}$. $\mathrm{cm}), \mathrm{R} 2=2350(\mathrm{~kg} / \mathrm{sq} . \mathrm{cm})(\mathrm{VSN}-2-26-71,1971)$.

\section{Results}

Let's consider the stressed-deformed state of the aboveground oil pipeline represented on the Figure 3 . Figure 3 shows the installation position of the pipeline - in green, and red - the position of the pipeline during the operation. 


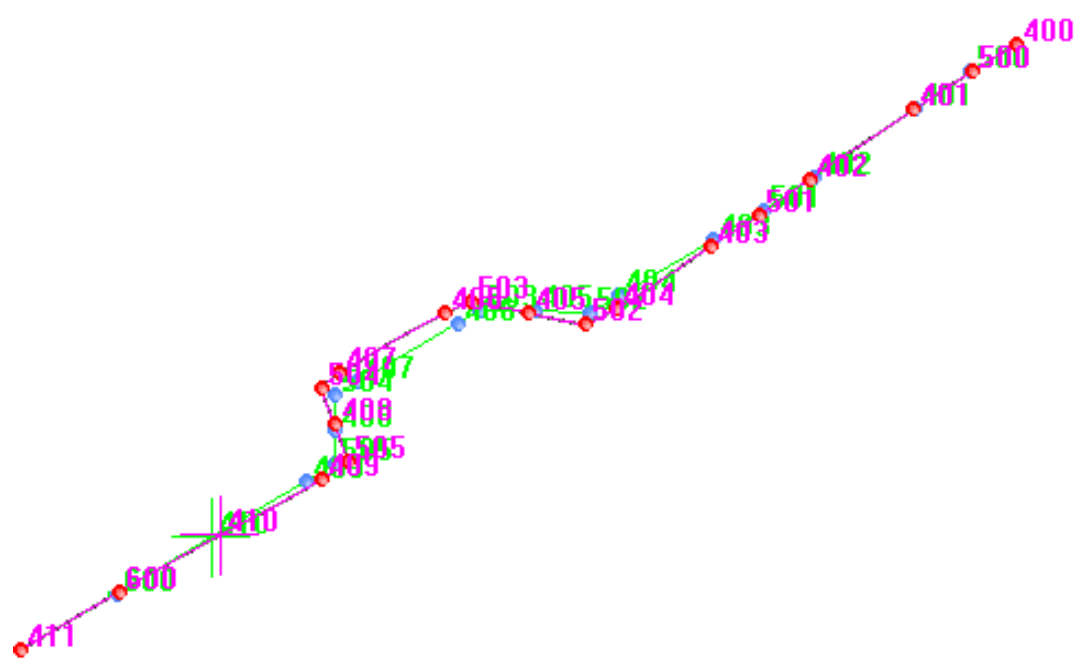

Figure 3. Aboveground pipeline behavior during its operation

As seen from the program calculations and also the graphical calculation results presentation window, during the operation stage considered pipeline would be mostly displaced at the supports \#404, 406, 407, 409. Modeled aboveground pipeline has the fixed supports at the beginning and at the end of the considering part. Accumulated during the operation stresses (due to the internal pressure in the pipe, thermal expansion, etc.) are distributed along the considered part of the pipeline between the two fixed supports. Since there is the compensator in the considering part, the stresses arising in the pipeline, maximally would be compensated on it, resulting in the displacement of the pipeline in the direction of least resistance - in this case displacement from the designed axis. In many cases the result of this displacement could be derailing of the aboveground pipeline from the pipeline support.

Software calculation results confidence confirm the field measurements. Before the stat-up of the pipeline lines was marked on the sliding support and on the support beam. After the start up of the pipeline reaching the project capacity it was noted that lines was displaced relative each other as it shown on the pictures 4 and 5 .
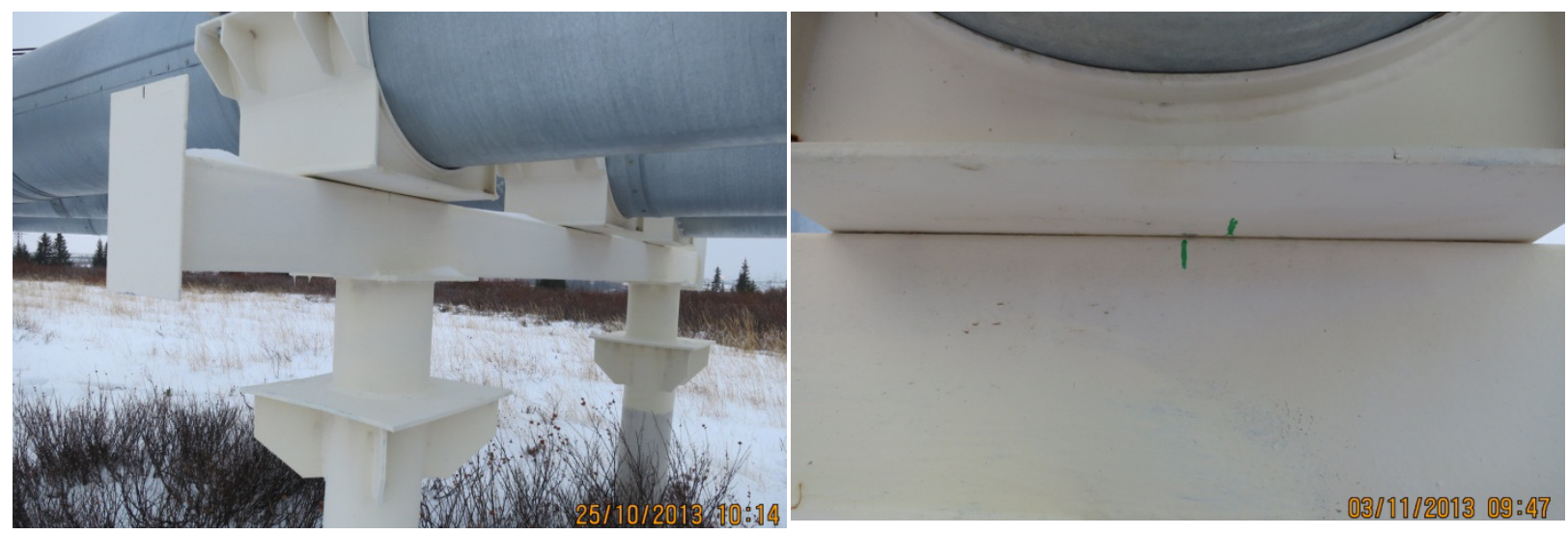

Figure 4. Displacement of the aboveground pipeline at the support \#407 

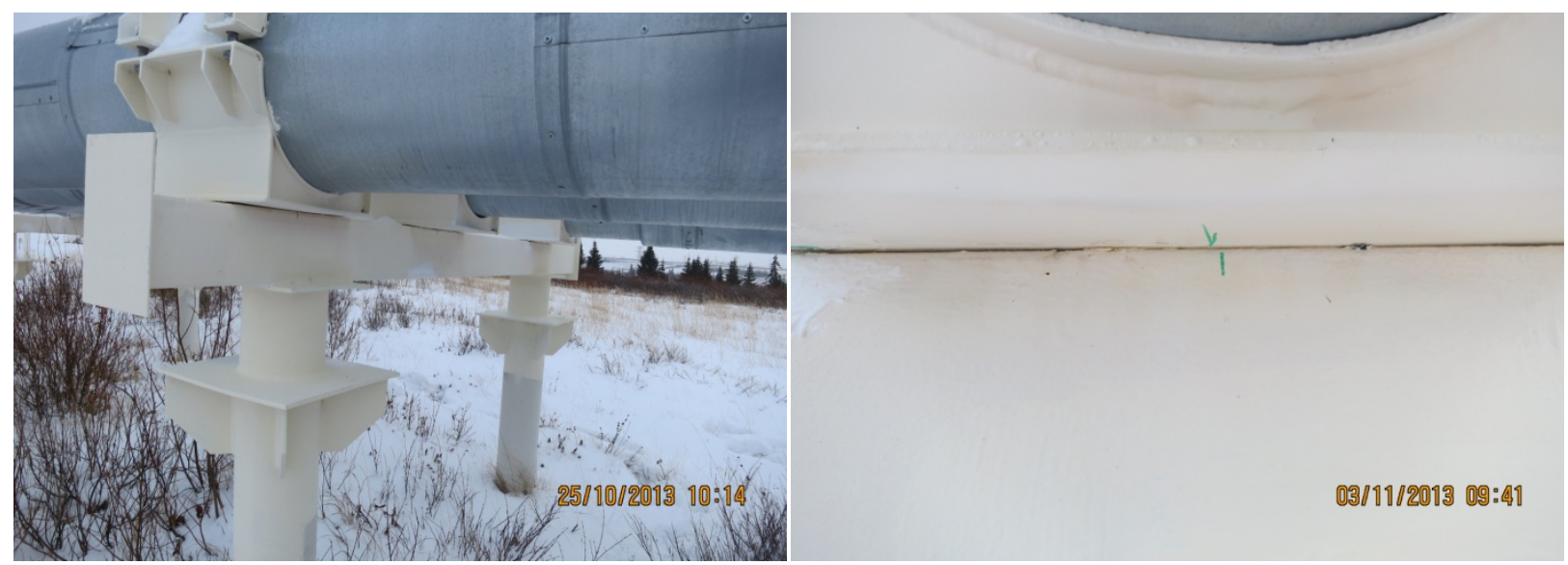

Figure 5. Displacement of the aboveground pipeline at the support \#409.

Software calculation results shows that the displacement of the pipeline from the Y-axis at the support \#407 would be $33,4 \mathrm{~mm}$ to the right downstream direction and displacement of the pipeline from the Y-axis at the support \#409 would be 12,5 mm to the left downstream direction. Field measurements confirm «Start» software calculations.

The total equivalent thee-dimensional displacement of the considered aboveground pipeline during the operation shown on the Figure 6.

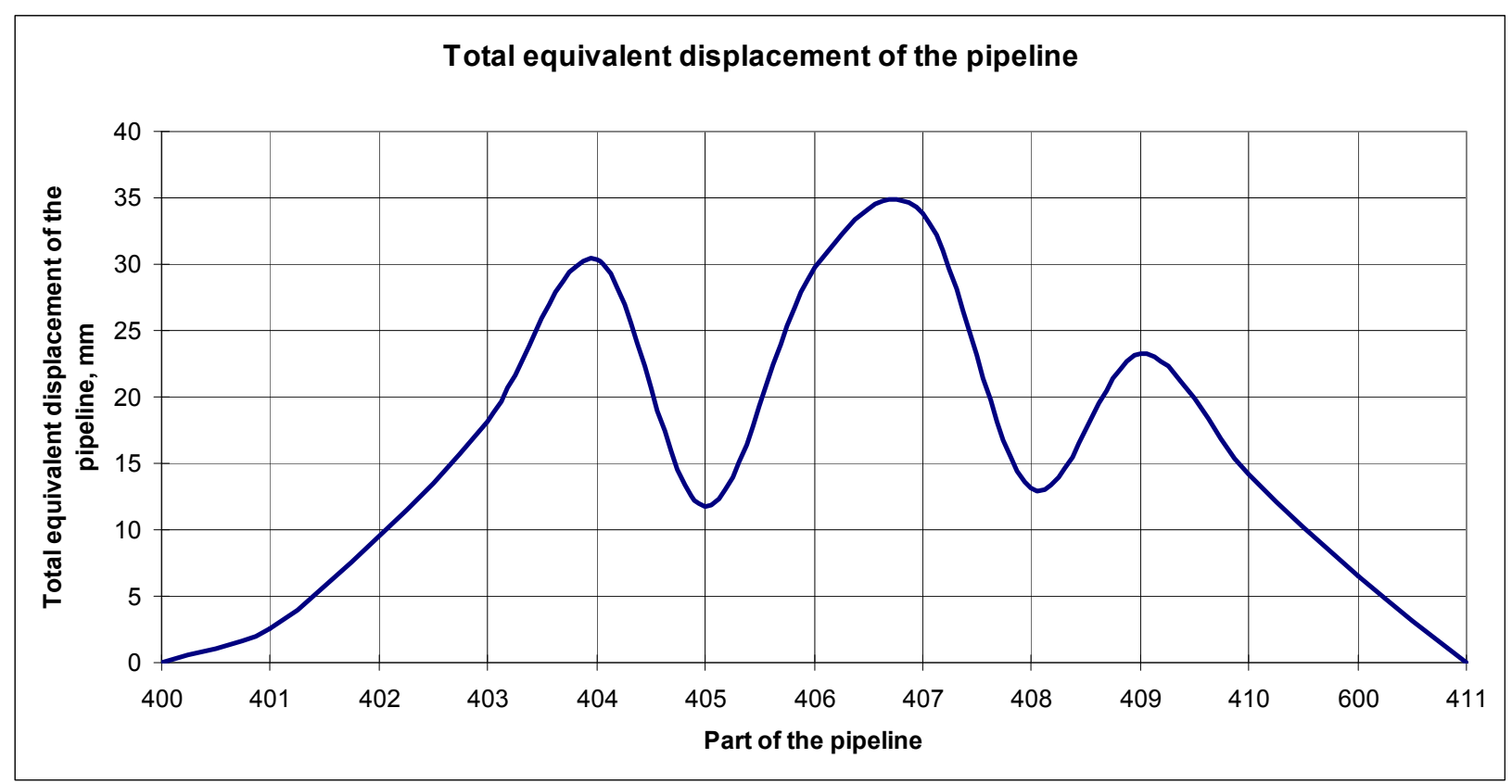

Figure 6. Diagram of the total equivalent displacement of the pipeline

Diagram shows that the largest displacements of the pipeline occur in the flexible areas - it means at compensation sites. The most displaced parts of the pipeline are at the supports \#404, 406, 407, 409 - where the elbows installed a shortest distance away. 


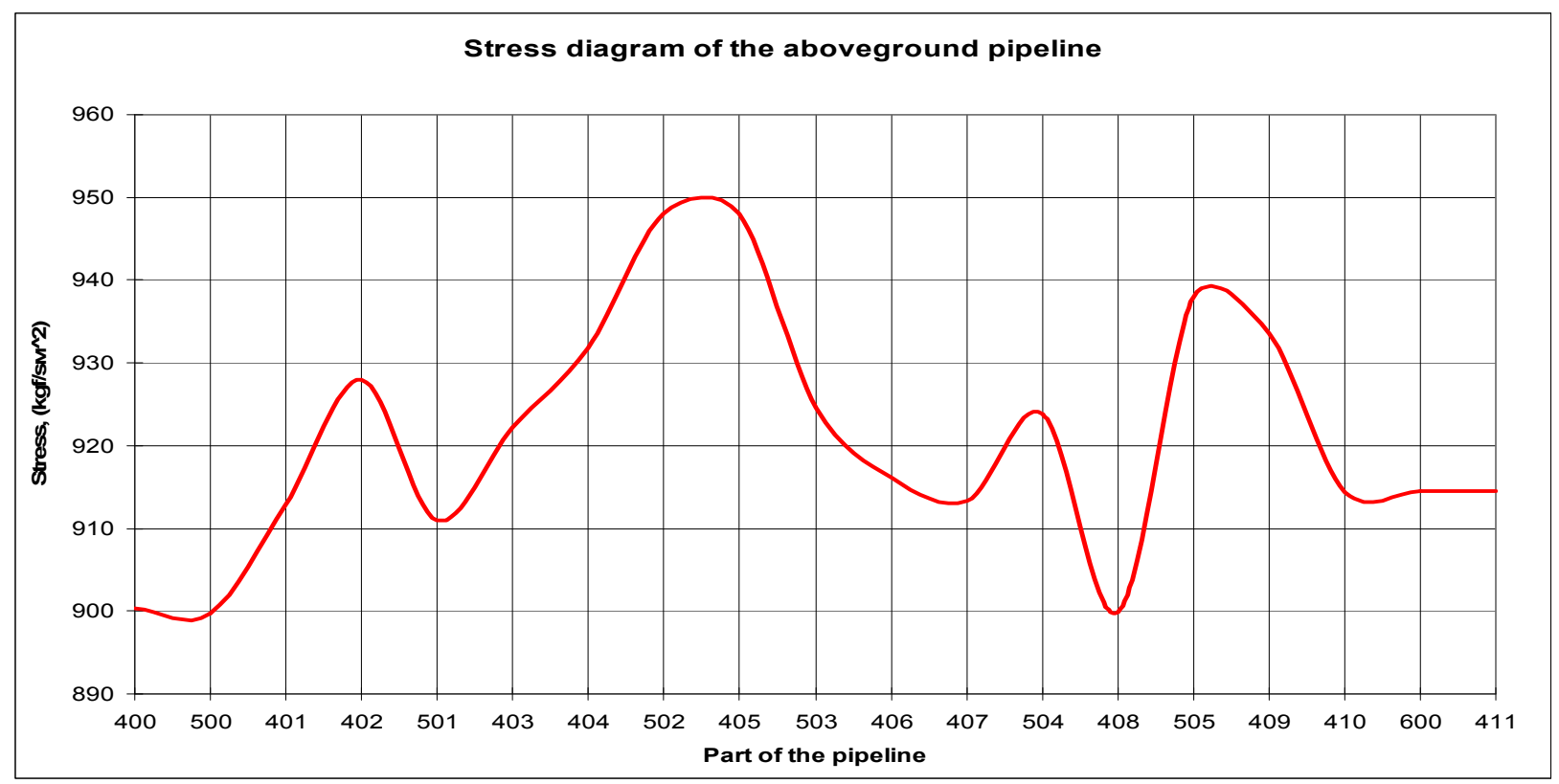

Figure 7. Diagram of the total equivalent stresses at the pipeline

Displacement of the pipeline it is the result of stresses arising during thermal expansion of the pipe sections, and this stresses are compensates at the pipeline bend points, thereby increasing the bending moment arising in a slightly curved parts. The diagram of the stress distribution along the all part of the considered aboveground pipeline shows that the maximum stresses would be located at the compensational part of the pipeline. Rising of the stresses due to the arising bending forces explain the highs of the stresses close to the elbow parts of the pipeline (see Figure 7). Based on our calculations we can say that the compensation sections of the pipeline are the most critical sections of aboveground pipeline. Design of the pipelines without compensation parts impossible due to the necessity of unloading the stresses in the pipeline occurs during the operation.

Let's consider the necessity of pipeline compensation parts, and in case of their essentiality determine compensator optimal configuration. To do this we have modeled in "Start" section of the pipeline without compensation part - with a straight section of the pipeline. Figure 8 shows this section of the pipeline without the compensation part.

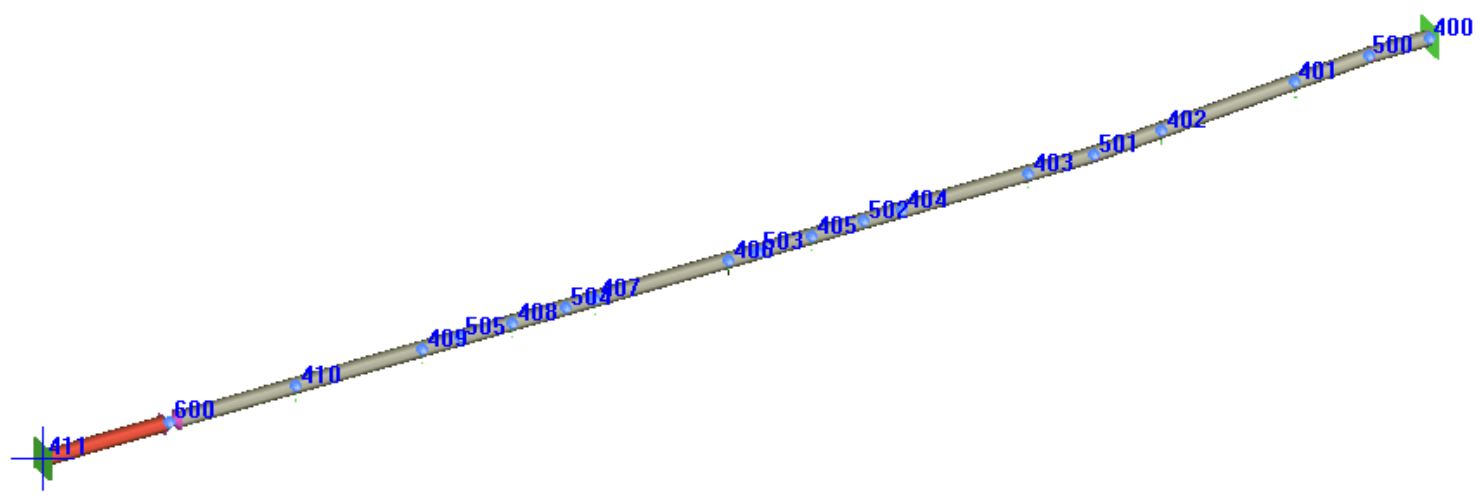

Figure 8. Modeled part of the above ground oil pipeline without compensation part in «Start» software

Then we have modeled similar sections of the pipeline with the elbows $15^{\circ}, 30^{\circ}, 45^{\circ}, 60^{\circ}, 75^{\circ}$ and $90^{\circ}$ at the compensation parts. First we estimated the total equivalent displacement of the pipeline sliding supports depending on the elbow angles. In addition to the displacements of the pipeline, at the same time, for a full analysis and evaluation of the given pipeline part, we have considered the stress-deformed state of the pipeline in 
its areas depending on the elbow angles at the compensator. Considering the case with a pipeline without compensator part we have discovered unacceptable $120 \mathrm{~mm}$ displacement of the pipeline at the support \#401the closest point to the elbow, necessary to achieve the contour of the pipeline route. Moreover due to the absence of compensation stresses sections the maximum stresses from thermal expansion of the pipeline and internal pressure will be impact on to the fixed support at beginning of the pipeline, and to the bending stresses in the elbow. These stresses exceed the maximum permissible value, so such kind of design is not allowed. In the design of the pipeline section with a compensator $15^{\circ}$ the stress value along the length of the pipeline is significantly reduced, but the pipeline displacement in the compensation section is unacceptable - more than 165 $\mathrm{mm}$.

Compensator $30^{\circ}$ for this section of the pipeline creates quite large displacement values of the pipeline in the compensation section up to $65 \mathrm{~mm}$. And in case of operation characteristics change, extreme weather conditions, wind and temperature loads, this displacement might increase and become unacceptable.

Compensator $90^{\circ}$ for this section of the pipeline meets the stress-deformed state requirements of the pipeline and its displacement. The feasibility of using this type of compensator goes into the economical rationality area, as the use of this type of compensator increases the length of the pipeline (number of tubes). Moreover in the pipeline with such configuration might arise additional hydraulic resistance and hydraulic shock. Also with such kind of elbows it is difficult to use some kind of pipeline pigs and diagnostic devices. Similar, but a lesser degree, conclusions also apply to the compensator with $75^{\circ}$ elbows.

Analyzing the data obtained it could be concluded that the compensation sections with $45^{\circ}$ and $60^{\circ}$ elbows are acceptable from the values of stresses and the pipeline displacements points of view. The decision to choose the type of compensator in each case would be taken individually depending on the length of the section between the fixed supports, stress values requiring compensating, wind and temperature load, technical and economic characteristics.

\section{Discussion}

The issue of the structural strength of pipelines in operation stage has the high importance. This question has been studied for several decades ago with the beginning development of areas with difficult climatic conditions (Kamerstein at el., 1969). The main parameters for the aboveground pipelines strength estimation are designed resistance R1 and the calculated yield strength designed resistance of R2. Most of the calculations reduced to the sufficient pipeline wall thickness determination at the given operation parameters. Subsequently, there were works of evaluating the pipelines strength as under the static load as under dynamic. It was investigated the methods of pipeline strength and durability calculations, after alternative calculation methods have been proposed (Sokolov and Limar, 2009). The pipelines deformations at operation were also investigated and several suggestions were offered for the pipeline operation reliability increasing (Spiridonov and Sverdlov, 1971). Particular attention has been paid to the pipeline laying scheme: straight and with compensators in the form of low sinuosity pipe sections (Spiridonov and Svarts, 1974).

Some works have been dedicated to the calculation of the bearing capacity of pile supports aboveground piping that was the proposal of constructive measures to improve their reliability (Kharionovskiy, 1990). Were analyzed correspondances between high-altitude position of the pipeline support and its stress-deformed state (Bykov at el, 2012). Also, researchers suggested using of the frame pipeline crossing and its improvement based on the stress-deformed analysis (Avtakhov, 2004). One of the important parameters affecting the operation of the above-ground pipelines is wind flow. Necessary to provide aerodynamic stability of the pipeline as a whole, as well as individual elements. Criteria for assessing the aerodynamic stability of the pipeline must be in the list of obligatory check, as well as considered in the design of above-ground pipelines (Kuzmin at el, 2006). Wind flow and the fluid flowing through the pipeline could have a significant impact on the oscillation frequency of the pipeline, which affects the total stability of the system (Sokolov, 2012).

Deformations of the aboveground pipeline are not critical if they are within acceptable ranges (Vitchenko and Bereznyakov, 2008). It is important to develop a system of evaluation of the stress-deformed state aboveground the pipeline after its commissioning (Vitchenko, 2008). Evaluation of stress-deformed state of pipelines with the help of modern computer products and techniques has also been studied in modern science (Lalin and Yavarov, 2010).

\section{Conclusion}

Thus, analyzing the calculation results, it must be concluded that the compensation sections on the pipeline are essential but the decision of choice the compensator and pipeline route geometric parameters, should be 
performed, guided not only meet the conditions of strength, as well as other reasonable important factors: the values of the forces acting on the fixed supports, three-dimensional position of the pipeline during hydraulic testing and operation, vibration in the pipeline, the impact of ambient temperature, wind resistance aboveground pipeline, further arising forces affecting piping supports, due to thawing of ground and soil bulging, etc.

It is necessary to check the reliability of the pipeline for each parameter of estimation and in case of dissatisfaction with one of the parameter appropriate adjustments should be made. Should take into account that the made corrections can positively affect on the checking to one of the criteria and negatively affect to the other. Therefore, a comprehensive and in-depth analysis is required.

Perspectives of research - an assessment of the stress-deformed state of the pipeline and its position taking into account all factors of influence: vibration, temperature, wind, etc. It is important to be able to assess the reliability of the pipeline for critical scenarios simultaneously, provide the opportunity to assess the reliability of the pipeline based on the probability of occurrence of these scenarios. The results of the study should be the main proposals to increase the reliability of the pipeline, the recommendations on basic design moments (placement of fixed supports, road crossing design, design of compensation areas), taking into account topography, soil conditions, the ambient temperature and other factors.

\section{References}

Abovskiy N. P. (2005). Construction in the northern oil and gas regions of the Krasnoyarsk Territory.: KrasGASA, Krasnoyarsk. ISBN 5-89628-136-6. pp. 228.

Ainbinder, A. B., \& Kamerstein, A. G. (1982). Pipelines calculation for strength and stability. Resource book. Nedra, Moscow. pp. 341.

Avtakhov, Z. F. (2004). Improvement effectiveness of using of frame pipeline crossing. Dissertation for the degree of Doctor of Philosophy, Ufa State Petroleum Technological University, Ufa, Russian Federation. UDK 621.644.074.3(043)

Borodavkin, P. P., \& Berezin, V. L. (1974). Construction of pipelines. Nedra, Moscow. UDK: 621.643 .002 (075.8). pp. 407.

Borodavkin, P. P., Berezin, V. L., \& Ruderman, S. U. (1974). Selection of optimized pipelines routes. Nedra, Moscow. pp. 240.

Bykov, L. I., Kotov, M. Y., \& Murasov, T. T. (2012). Assessing the influence of changes of supports high-altitude position to the stress-deformed state of beam crossings. Transport and storage of petroleum and of hydrocarbons, 1, 7-12. Retrieved from http://elibrary.ru/item.asp?id=17787913

Kamerstein, A. G., Rogdestvenskiy, V. V., \& Ruchimskiy, M. N. (1969). Pipeline stress analysis. Resource book. Nedra, Moscow. UDK 625.9(03). pp. 440.

Kharionovskiy, V. V. (1990). Strength improvement of the gas pipelines at difficult conditions. Nedra, Moscow. UDK 621.643.002.2. pp. 180.

Khrenov, N. N., (2005). Basics of integrated diagnostic of northern pipelines. Gas press, Moscow. ISBN 5-87719-008-3. pp. 606.

Kuzmin, S. V., Zakuraev, A. F., \& Ivanov, V. A. (2006). Aerodynamic calculation methods of aboveground pipelines. University news. Oil and gas, 1(62-66). Retrieved from http://mars.arbicon.ru/index.php?mdl=content\&id $=38520$

Lalin, V. V., \& Yavarov, A. V. (2010). Modern calculation technologies of main pipelines. Engineering and construction magazine, 3(43-47). Saint-Petersburg. Retrieved from http://www.engstroy.spb.ru/index_2010_3/yavarov.html

Petrov, I. P., \& Spiridonov, V. V. (1973). Aboveground pipelining. Nedra, Moscow. pp. 472.

Shammazov, A. M., Zaripov, R. M., Chichelov, V. A., \& Korobkov, G. E. (2005). Calculation and ensuring the strength of the pipelines in difficult engineering-geological conditions. Inter, Moscow. ISBN 5-98761-006-0. pp. 706

SNiP 2.05.06-85 Construction norms and rules. Pipelines. (1985). Retrieved from http://xn--h1ajhf.xn--p1ai/snip/view/95

Sokolov, S. M., \& Limar, O.V. (2009). Above-ground main pipelines calculation and durability test. Oil industry. 6(86-90). Retrieved from http://www.oil-industry.ru/archive_detail_en.php?ID=8714 
Sokolov, V. G. (2012).Vibrations, static and dynamic stability of large diameter pipelines. Dissertation for the degree of Doctor of Philosophy, Saint-Petersburg State University of Architecture and Civil Engineering, Saint-Petersburg, $\quad$ Russian $\quad$ Federation. Retrieved from http://www.dissercat.com/content/kolebaniya-staticheskaya-i-dinamicheskaya-ustoichivost-truboprovodovbolshogo-diametra

Spiridonov, V. V., \& Svarts, L. E. (1974). Investigation of aboveground pipelines with low sinuosity pipe sections. VNIIST issue, 29(95-100).

Spiridonov, V. V., \& Sverdlov, M. F. (1971). Aboveground pipelines deformability investigations. VNIIST issue, 25(230-245).

Vitchenko A. S. (2008). Control of pipelines stress-deformed condition at permafrost. Dissertation for the degree of Doctor of Philosophy, Engineering and technical science, Nadym, Russian Federation. Retrieved from $\mathrm{http} / /$ www.dissercat.com/content/kontrol-deformirovannogo-sostoyaniya-nadzemnykh-truboprovodov-v-kr iolitozone

Vitchenko, A. S., \& Bereznyakov, A. I. (2008). Determination of the allowable deformation parameters of pipeline interconnections on the gas fields, operated in at Far North. Science \& Technology in the Gas industry, $\quad 4, \quad 104-109 . \quad$ Retrieved from http://naukaitechnika.ru/index.php?option=com_content\&task=view\&id=58\&Itemid=19

VSN-2-26-71. (1971). Instructions of pipeline design with the longitudinal deformations compensation. Mingazprom, Moscow. pp. 258.

\section{Copyrights}

Copyright for this article is retained by the author(s), with first publication rights granted to the journal.

This is an open-access article distributed under the terms and conditions of the Creative Commons Attribution license (http://creativecommons.org/licenses/by/3.0/). 